\title{
Intercomparison of multiple years of MODIS, MISR and radar cloud-top heights
}

\author{
C. M. Naud ${ }^{1, *}$, J.-P. Muller ${ }^{1}$, E. E. Clothiaux ${ }^{2}$, B. A. Baum ${ }^{3}$, and W. P. Menzel ${ }^{4}$ \\ ${ }^{1}$ University College London, Department of Geomatic Engineering, Gower Street, London WC1E 6BT, UK \\ ${ }^{2}$ The Pennsylvania State University, Dept. of Meteorology, 603 Walker Building, University Park, PA 16802, USA \\ ${ }^{3}$ NASA/Langley Research Center, Hampton, VA 23681, USA \\ ${ }^{4}$ NOAA/NESDIS, 1225 W. Dayton St., Madison, WI 53706, USA \\ *now at: Columbia University, 2880 Broadway, New York, NY 10025, USA
}

Received: 24 June 2005 - Revised: 10 August 2005 - Accepted: 17 August 2005 - Published: 14 October 2005

\begin{abstract}
Radar cloud-top heights were retrieved at both the Chilbolton Facility for Atmospheric and Radio Research, UK (CFARR) and the ARM Southern Great Plain site, USA (SGP), using millimetre wave cloud radars and identical algorithms. The resulting cloud-top heights were used for comparison with MODIS and MISR retrieved cloud-top heights, from March 2000 to October 2003. Both imaging instruments reside on the NASA Earth Observing System (EOS) Terra platform launched in 1999. MODIS and MISR cloud-top products were from the recent collections (4 and 3, respectively) that cover the entire mission. The cloud characteristics are different at each ground site, with clouds generally residing at higher altitudes at SGP, but with a greater occurrence of broken or multilayered clouds at CFARR. A method is presented to automatically eliminate scenes where clouds are of a broken nature, since it is difficult in these conditions to ensure that ground-based and satellite measurements refer to the same cloud deck. The intercomparison between MODIS and radar cloud-top heights reveals that MODIS cloud-top heights agree with radar within about $1 \mathrm{~km}$ for mid- and high-level clouds. However, this accuracy is degraded to nearly $3 \mathrm{~km}$ for low-level clouds. MISR cloud-top heights are found to agree with radar cloud-top heights to within $0.6 \mathrm{~km}$, which is in line with theoretical expectations. In single-level cloud situations MODIS and MISR cloud-top heights tend to agree within $1 \mathrm{~km}$. This comparison also reveals that the loss of radar sensitivity during 2001 resulted in the CFARR instrument being less accurate for high-level cloud-top height measurements.
\end{abstract}

Keywords. Atmospheric composition and structure (Instruments and techniques)

Correspondence to: C. M. Naud

(cnaud@giss.nasa.gov)

\section{Introduction}

The principal objective of this work is to provide an independent assessment of satellite-based, cloud-top pressure/height products that are produced operationally for the Moderate resolution Imaging Spectrometer (MODIS) and the Multi-angle Imaging SpectroRadiometer (MISR) instruments. Both instruments are on NASA's Earth Observing System (EOS) Terra platform that was launched on $18 \mathrm{De}$ cember 1999. While MODIS has unprecedented spectral coverage in key atmospheric bands and an instantaneous field of view of $1 \mathrm{~km}$ (or better) at nadir, MISR has a set of 9 cameras at angles from $\pm 70^{\circ}$ to nadir, aligned in the along-track direction that records data at four wavelengths at a nominal resolution of $275 \mathrm{~m}$. The cloud products derived from these two instruments are based on quite different methods: MODIS radiometric methods versus the MISR geometric derivation. As will be discussed further throughout this article, each method has strengths and weaknesses that can be evaluated through comparison with independent cloud boundary assessments derived from ground-based radar. The focus of this investigation is to compare the Terra platform cloud-top pressure/height product from both MODIS and MISR to ground-based cloud observations from two surface sites.

The Terra platform is in a Sun-synchronous, near-polar orbit at a nominal altitude of $705 \mathrm{~km}$. Because of its wide cross-track scanning swath $(2330 \mathrm{~km})$, MODIS views the entire surface of the Earth every one or two days (Salomonson et al., 1989), while MISR has a more limited swath width $(380 \mathrm{~km})$ that produces global coverage every 9 days (Diner et al., 1998). The MODIS cloud-top pressures are available, at the time of writing, as a Level-2 MOD06 collection 4 product (Platnick et al., 2003); cloud-top heights are derived through use of ECMWF operational analysis profiles. MISR cloud-top heights are from the latest collection (versions F05 and F06, recently renamed collection 3) of the MISR level 
2 top-of-atmosphere/cloud product (L2TC). The use of the term "collection" refers to the reprocessing level of each data stream. Each time the data processing algorithm and/or calibration is updated significantly, all the data acquired since the beginning of the mission is reprocessed. The resulting data-set is then referenced to a specific collection number.

This work builds upon previous efforts to assess MODIS and MISR cloud-top heights as described heretofore. Frey et al. (1999) used the airborne version of MODIS, called the MODIS Airborne Simulator (MAS), and compared cloudtop pressures (obtained with the same algorithm as the one implemented for Terra and Aqua) with cloud-top pressures derived from a downward pointing lidar on-board the same NASA ER-2 aircraft. They found an agreement within $0.5 \mathrm{~km}$ for most single-layered clouds, with errors increasing under multilayered cloud conditions. The best agreement was found for optically thick clouds, while comparisons were more problematic for a) optically thin, but geometrically thick clouds, such as cirrus and b) multilayered clouds consisting of thin cirrus overlying a low-level water cloud. With data from the AirMISR instrument, an airborne version of MISR, Marchand et al. (2001) tested the MISR operational algorithm against the aircraft lidar, finding agreement to within about $0.5 \mathrm{~km}$. Naud et al. $(2002,2004)$ compared MISR and MODIS cloud-top heights with groundbased radar and lidar on a limited data-set and again reasonable agreement (to within $2 \mathrm{~km}$ ) was found as long as the clouds were not multilayered for MISR and of sufficient optical thickness for both. Mace et al. (2005) compared MODIS and ground-based measurements of cirrus cloud properties at the SGP site and found a MODIS cloud-top height underestimation for thin clouds.

This study uses a larger data-set than that reported in Naud et al. (2002; 2004) and encompasses an assessment period from March 2000 through October 2003. MODIS and MISR products are evaluated from the latest processing algorithm (Collection 4 for MODIS and Collection 3 for MISR). Surface-based data are taken at two different locations that have quite different cloud climatology characteristics (i.e. marine-UK and central continental-US). The two surface sites are the Chilbolton Facility for Atmospheric and Radio Research (CFARR), Hampshire, UK $\left(51.15^{\circ} \mathrm{N}-1.43^{\circ} \mathrm{W}\right)$ and the Atmospheric Radiation Measurements (ARM) program Southern Great Plains (SGP) site in Oklahoma $\left(36.62^{\circ} \mathrm{N}-97.5^{\circ} \mathrm{W}\right)$. Clouds tend to reside in a bimodal distribution at the SGP site, primarily consisting of low-level and high-level clouds, while mid-level clouds occur more often at the Chilbolton site.

Precise measurements of cloud-top heights can be obtained with active instruments, such as millimetre wave cloud radars that can reach an accuracy of better than $150 \mathrm{~m}$ for cloud boundaries (Clothiaux et al., 2000). The millimetrewave cloud radar (MMCR) data for both sites were obtained, from which radar-derived cloud-top heights were extracted for intercomparison with MISR and MODIS. The 3.5-year time period for the comparison is limited by the start of the MODIS and MISR processing and the availability of radar data during this period. Both radar processing chains were interrupted at the time of this study - September 2003 for SGP and October 2003 for CFARR.

Section 2 describes the data sources and products. Section 3 presents the intercomparison approach together with its limitations. Section 4 describes the results from intercomparisons between MODIS and radar, MISR and radar, and MODIS and MISR. Concluding remarks follow in Sect. 5.

\section{Data}

We first describe the MODIS, MISR and cloud radar data products, as well as what criteria were used to select scenes for intercomparison and identify potentially problematic cases. We also include a discussion of the strengths and limitations of these instruments for retrieving cloud-top heights.

\subsection{MODIS}

MODIS measures radiances in 36 spectral bands, using four focal planes covering the spectral range from $0.4-14.2 \mu \mathrm{m}$. The spatial resolution for nadir views varies from $250 \mathrm{~m}$ to $1 \mathrm{~km}$, depending on the spectral band. The MODIS cloud products are generated on a granule basis; a granule is $5 \mathrm{~min}$ of orbit data and typically consists of 2030 along-track and 1350 across-track $1-\mathrm{km}$ resolution pixels.

The suite of operational cloud products begins with cloud detection or masking, i.e. deciding whether or not a cloud is present within a pixel (Ackerman et al., 1998). Infrared techniques are employed to estimate cloud-top pressure, effective cloud amount (product of cloud fraction and cloud emittance), and cloud thermodynamic phase from 5-km averaged radiances. Further discussion of the cloud products is provided in Platnick et al. (2003) and King et al. (2003), so only a brief description of cloud-top pressure retrieval is provided here.

MODIS cloud-top pressures are calculated operationally using the $\mathrm{CO}_{2}$-slicing technique (Menzel et al., 1983, 2002; Wylie and Menzel, 1999; Wielicki and Coakley, 1981; Baum and Wielicki, 1994), although this method is best suited to mid- and high-level clouds. In the MODIS algorithms cloudtop pressure is converted into cloud-top temperature through the use of a gridded meteorological product that provides relevant profiles at some nominal vertical resolution every $6 \mathrm{~h}$. The product for this purpose is provided by the National Center for Environmental Prediction (NCEP) Global Data Assimilation System (GDAS; Derber et al., 1991). Due to signal-to-noise issues, $\mathrm{CO}_{2}$-slicing cloud-top pressures are generally limited to the range from approximately $700 \mathrm{hPa}$, i.e. about $3 \mathrm{~km}$ above sea-level, up to the tropopause. When low clouds are present, the MODIS algorithms defer to the infrared window technique, where cloud-top pressure and temperature are determined through comparison of modelcalculated and observed $11 \mu \mathrm{m}$ radiances.

Because cloud-top pressure and temperature, but not height, are provided in the MOD06 suite of data products, 
we use ECMWF profiles to convert cloud-top pressures into (geopotential) cloud-top heights. We chose to use ECMWF meteorological profiles because they were readily available to us at the time of our study with the Collection 4 MOD06 data products.

\subsection{MISR}

MISR is a push-broom imager that observes the Earth in three visible channels $(0.446,0.558,0.672 \mu \mathrm{m})$ and one nearinfrared $(0.866 \mu \mathrm{m})$ channel at a nominal along-track resolution of $275 \mathrm{~m}$ ( $250 \mathrm{~m}$ for nadir) at along-track view zenith angles of $0^{\circ}, \pm 26.1^{\circ}, \pm 45.6^{\circ}, \pm 60.0^{\circ}$, and $\pm 70.5^{\circ}$. The swath width is $380 \mathrm{~km}$ across-track (Diner et al., 1998). The nominal resolution of the cloud-top height product is $1.1 \mathrm{~km}$. Because of its narrow swath, the time needed for global coverage is 9 days. However, each mid-latitude location on Earth is observed within at least three distinct orbits during the TERRA 16-day ground track repeat cycle, making it possible to obtain measurements 5 to 6 times a month over a given site, depending on latitude. The MISR retrieval technique for cloud-top height is based on a stereoscopic method that uses images of the same cloud obtained from both pairs of the innermost three cameras, i.e. the MISR nadir and $\pm 26.1^{\circ}$ view zenith cameras (Moroney et al., 2002; Muller et al., 2002). Stereoscopic techniques have been applied to cloud height retrievals for more than 20 years now, in particular from geostationary data (e.g. Hasler, 1981; Wylie et al, 1998). Stereo cloud-top heights were found to be in good agreement with techniques such as $\mathrm{CO}_{2}$-slicing, with a similar tendency to be tuned to the level of greater contrast within the cloud but not necessarily at the cloud-top (Wylie and Menzel, 1989; Naud et al, 2004). However, these measurements were not applied routinely and only covered specific regions, thus it is only recently that stereo retrievals could be automated (see Muller et al., 2002 for more details).

The primary advantage of MISR cloud-top height retrieval is that it is purely geometric and does not rely on any additional scene information. However, because of the time delay between consecutive MISR camera views (about $45 \mathrm{~s}$ between the nadir and one of the closest cameras at $\pm 26^{\circ}$ of one location), wind advection of clouds can often cause errors in MISR cloud-top height retrievals. For this reason winds are first retrieved. If a wind retrieval is deemed successful, wind-corrected cloud-top heights are extracted (Zong et al., 2002). The product corrected for wind advection is named the BestWind cloud-top height product, but an uncorrected product is also available and called the WithoutWind cloudtop height product. Both products are available in the MISR level 2 top-of-atmosphere/cloud stereo operational product but BestWind cloud-top heights are only used here; with the WithoutWind product only being used to assess the cause of a missing retrieval. The MISR stereo cloud-top height retrieval algorithm and preliminary results obtained from it are summarized in Muller et al. (2002).

\subsection{Millimetre wavelength cloud radar}

A 35-GHz MMCR is operated continuously at the ARM program SGP site. These radar data are processed and archived automatically. Similarly, the CFARR 94-GHz MMCR operates in an automated mode. Both radars are vertically pointing and have fairly similar characteristics. We applied the radar data processing algorithm developed by Clothiaux et al. (2000) to the data-sets from both radars. In our timeseries analyses we used the quality control (QC) reflectivity clutter flag, which provides a cloud mask flag every $10 \mathrm{~s}$ at a vertical resolution of $75 \mathrm{~m}$. The cloud mask flag distinguishes between no data, clear (i.e. no significant atmospheric power return), clouds (i.e. significant atmospheric power return from hydrometeors), pure clutter (i.e. significant atmospheric power return from non-hydrometeors) and mixtures of clutter and clouds. Clutter is a generic term for non-hydrometeor objects, such as insects or vegetal debris. MMCRs have the advantage of being able to detect multilayered clouds, so a full vertical profile of cloud occurrence is available. However, they are not sensitive to small cloud particles far from the radar, and experience problems in identifying the presence or absence of cloud particles in regions of precipitating raindrops. Consequently, cloud base is difficult to detect with a MMCR when the cloud is precipitating. To overcome this problem the base of the lowest cloud layer in the column above the radars is retrieved using additional data from a micropulse lidar at the SGP site and a conventional Vaisala ceilometer at CFARR.

\section{Intercomparison methodology}

\subsection{Data selection}

The radar data are sampled over time periods centred on the Terra overpass time. We examined only those Terra orbits for which the narrower swath of MISR encompasses the radar site. As a result, only 5 to 6 Terra orbits per month contributed to our study. We varied the radar sampling time periods between $600 \mathrm{~s}$ (or $\pm 5 \mathrm{~min}$ centred on the MODIS overpass time) to $4800 \mathrm{~s}$ (or $\pm 40 \mathrm{~min}$ ). To characterize the different types of clouds over each site, we found that the 600 s sampling periods were sufficient for the ARM SGP site, whereas the $4800 \mathrm{~s}$ periods were necessary at CFARR, because of the broken nature of the clouds at this site. Radar median cloud-top heights were derived for each period, as were the corresponding number of cloud layers.

Although both the ARM SGP and CFARR sites are situated at mid-latitudes, their climates are very different. The CFARR site is strongly influenced by the Atlantic Ocean to the west and the North Sea to the east. In contrast, the SGP site is situated at the centre of the United States. The height of the tropopause is located typically at $13 \mathrm{~km}$ at CFARR but $16 \mathrm{~km}$ at the SGP site. Clouds tend to be equally distributed in height at the SGP site (Fig. 1), whereas low-altitude clouds (below approximately $3 \mathrm{~km}$ ) are predominant at the CFARR 


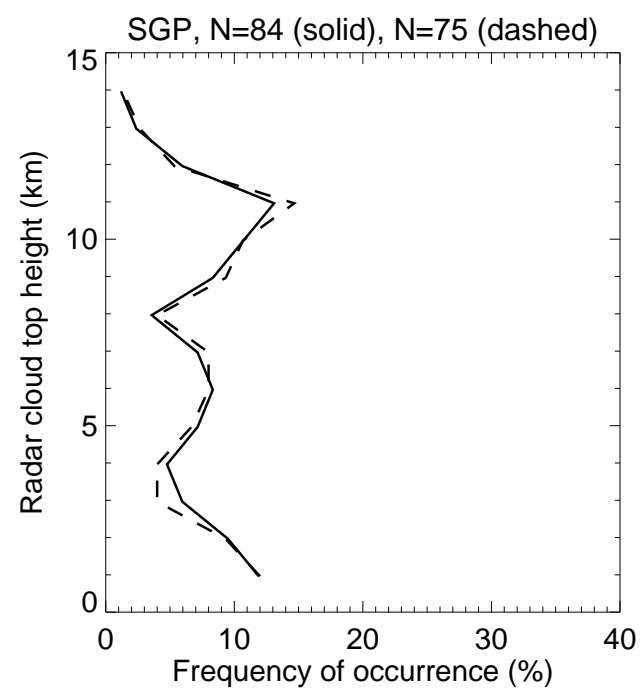

Fig. 1. Cloud-top height frequency of occurrence for all dates with radar data at SGP (solid line) and for cases that obeyed the three thresholds imposed for removing broken cloud cases (dashed line). The cloud-top heights correspond to the median calculated over the $600 \mathrm{~s}$ time period.

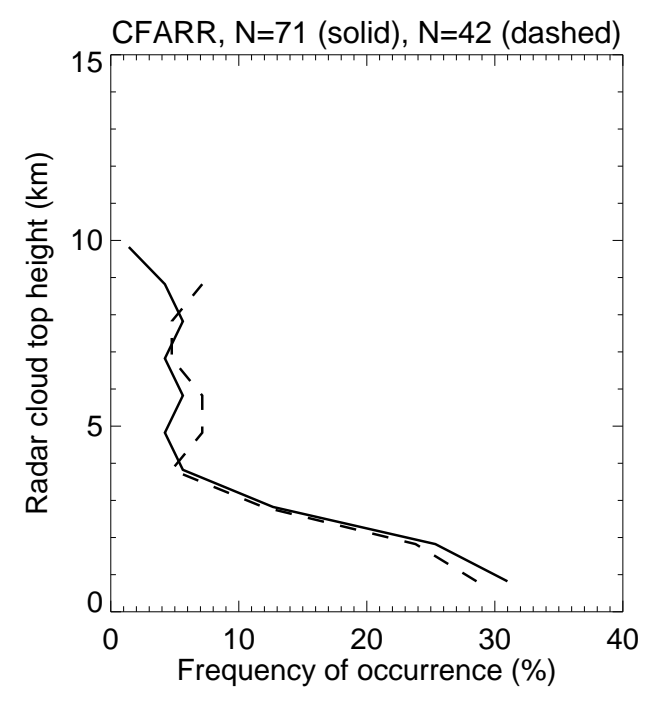

Fig. 2. Same as Fig. 1 for the CFARR site, with median cloud-top heights calculated over a $4800 \mathrm{~s}$ time period centred on MODIS start of acquisition time.

site (Fig. 2), reflecting the much greater influence of marine stratus clouds at the UK site. Additionally, clouds are more often multilayered vertically and non-uniform horizontally (i.e. broken) at CFARR.

Broken cloud situations cause problems finding match-ups between ground-based time series with instantaneous satellite views, and multilayered clouds present different retrieval issues for both MODIS and MISR. Naud et al. (2002, 2004) showed that MISR stereo height retrievals were sensitive to multiple cloud layer situations. MISR stereo heights tend to be assigned to the lower of the two cloud layers in its field of view, if the contrast in the lower cloud is larger. Consequently, we must identify scenes where optically thin clouds are above lower optically thick cloud. We used radarderived vertical profiles of cloud/no cloud classifications at $75 \mathrm{~m}$ resolution, to estimate the number of distinct cloud layers present above each site for each Terra overpass.

We found that no matter which time period we used for the radar sampling, there were still outliers where the radar reflectivity plots revealed broken layers or rapidly varying cloud-top heights in frontal situations. The assumption of frozen turbulence that allows the direct transformation from time series to spatial averages, assuming a constant wind speed, justifies the use of radar time series for comparison with satellite retrievals. However, additional tests had to be performed, in order to discard cases where large variations in cloud-top heights would cause disagreement between ground-based and satellite observations. Most of the broken cloud situations were eliminated from the study by keeping only cases for which the difference between the maximum and median radar cloud-top heights for a given time period did not exceed $3 \mathrm{~km}$; the standard deviation of the radar cloud-top height over the time period did not exceed $2 \mathrm{~km}$, and the fraction of cloudy pixels over the sampling period was at least $10 \%$. We rejected any case that did not pass these three tests. Figures 1 and 2 show how the distributions of radar cloud-top height vary when these cases are removed. As Fig. 1 illustrates for the SGP site, the frequency of occurrence of cloud as a function of altitude does not change much, implying that broken cloud situations are not frequent at this location and have little influence on the mean vertical CTH profile. On the other hand, Fig. 2 shows a decrease in the highest clouds and an increase in mid-level clouds at CFARR, revealing that situations with a broken high cloud layer are more frequent.

We initially sampled the MODIS and MISR cloud-top heights over latitude-longitude boxes of sizes $\pm 0.2^{\circ}, \pm 0.1^{\circ}$, $\pm 0.05^{\circ}$ and $\pm 0.02^{\circ}$, that were centred on the two sites. Since we found no significant differences in the results from one box size to the next and the 5-km resolution of the MOD06 cloud-top heights meant that there were often no results available for the small $\pm 0.02^{\circ}$ boxes, we used medians, means, and standard deviations of cloud-top height obtained from the large $\pm 0.2^{\circ}$ boxes for this study. We present only the median cloud-top heights as the most representative height within each box.

Since MODIS provides cloud-top heights derived using two different methods $\left(\mathrm{CO}_{2}\right.$-slicing and $11-\mu \mathrm{m}$ radiances/brightness temperatures, known hereafter as BT11), we distinguish between them. On some occasions, we found that both the $\mathrm{CO}_{2}$-slicing and the BT11 techniques were used in one $\pm 0.2^{\circ}$ box. This observation implied a broken cloud situation, where low and high clouds were present in the area around the radar. Subsequently, we set the criteria as follows: (a) the MODIS cloud fraction had to be $100 \%$ within the $\pm 0.2^{\circ}$ box for a case to be kept, and (b) only one retrieval method for all pixels within the box was permitted. 


\subsection{Limitations}

Although estimating the number of cloudy layers from the radar profiles appears to be an effective method of identifying cloud overlap situations in a vertical column, we visually inspected the profiles to discard any suspicious cases. For example, the ground-based radar at SGP observed one layer at a time for a heterogeneous multilayered cloud scene on 30 November 2000 (Fig. 3); a high cloud layer was present above the radar at the time of the overpass and a lower cloud layer appeared soon thereafter in isolation from the upper cloud deck. Because of the short sampling time period that we chose for the SGP site, only one cloud layer was included in the radar statistics for this case. However, both cloud layers were apparent in the MODIS cloud-top height map and both layers made contributions to the MODIS and MISR median cloud-top height statistics. This case is an illustrative example of broken cloud situations where the radar and satellite instruments will disagree because they do not necessarily observe the same cloud deck simultaneously. Cases like this one had to be manually eliminated. This type of situation and broken cloud situations are the main limitation for such a comparison where time series and instantaneous views are compared. Although the thresholds we introduced for both radar and MODIS data allowed for good match-ups between the various instruments, this meant that a much smaller number of cases could be kept in the inter-comparison datapool.

Another issue stems from the sensitivity of MMCRs to socalled "clutter", such as insects and vegetation debris (e.g. pollen) that are especially problematic at the SGP site. At the ARM SGP site this clutter can be detected at altitudes up to $5 \mathrm{~km}$. Although our cloud detection algorithms also rely on ceilometer measurements of cloud-base height, high altitude clutter can prevent reliable information on cloud-top heights. This clutter strongly affects all low-level cloud comparisons at the ARM SGP site, particularly during the summer. These cases were kept in the datapool but they may cause inaccuracies in radar cloud-top heights for low-level cloud situations.

Finally, MMCR radars lack sensitivity to small particles that often occur at the top of high-level ice clouds. Because the 35-GHz radar at SGP possesses a large antenna and powerful transmitter, it is believed to be accurate for ice clouds tops. However, this is not the case for the 94-GHz radar at CFARR, which in addition experienced technical problems during the period of comparison. During 2001 the sensitivity of the CFARR radar began monotonically decreasing and in March 2002 the radar failed altogether. The radar transmitter was replaced and full operations recommenced in April 2003. We attempted to identify if there were any trends in our results that were correlated with the drop in CFARR radar sensitivity but were unable to find any. However, as we discuss later, some of the observed differences between radarand satellite-derived cloud-top heights might be partially explained by the decrease in CFARR radar sensitivity during 2001 and the early part of 2002.
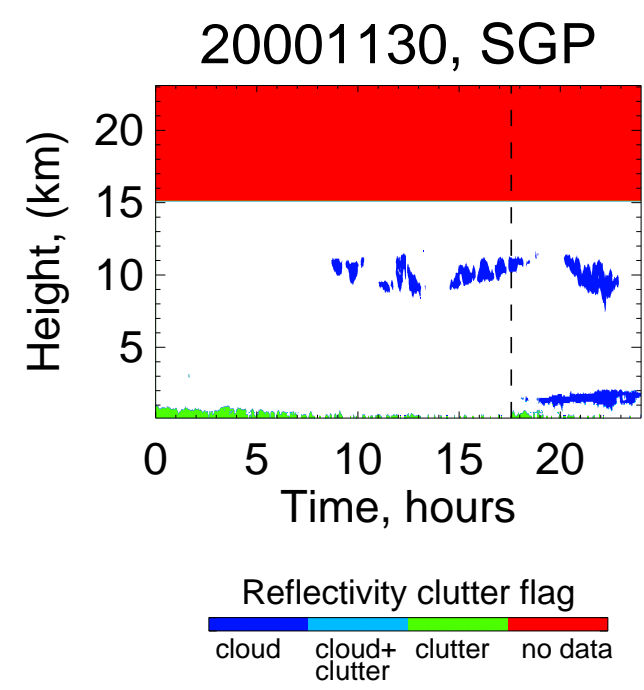

Fig. 3. Radar cloud mask for 20 November 2000, with clouds in dark blue, clutter in green, mix of clutter and hydrometeors in light blue and no returns in red. The dashed line represents the MODIS start time of acquisition over the site. This figure illustrates the complexity of some scenes where two different cloud layers appear above the radar beam at different times but will be present close to the site in the satellite images.

\section{Results}

In the next three sections we present statistics of the differences in cloud-top heights derived from the ground- and satellite-based instruments. We summarize these results in Table 1. The interested reader can find all the individual case studies for both sites illustrated on the UCL results section of the EU-CLOUDMAP2 web-page at http://cloudmap.org.

\subsection{Intercomparison between MODIS and radar cloud-top heights}

We initially found 82 cases at SGP and 71 cases at CFARR, with clouds detected by both radar and MODIS. Once all the ambiguous cases were eliminated, as described above, the cloud-top height comparison between MODIS and radar included 43 and 27 cases, respectively.

At SGP, 22 (out of 43) cases retrieved with $\mathrm{CO}_{2}$-slicing showed that MODIS cloud-top heights were lower than radar cloud-top heights by an average difference of $-1.2 \pm 1.0 \mathrm{~km}$. At CFARR, the same difference calculated for 10 (out of 27 ) cases gave an average difference of $0.6 \pm 1.3 \mathrm{~km}$. The standard deviations are roughly similar, indicating an accuracy between $1.0 \mathrm{~km}$ and $1.5 \mathrm{~km}$ when MODIS retrievals are performed with the $\mathrm{CO}_{2}$-slicing technique. The different signs for the bias come from the differences in cloud-top height distribution at the two sites. Figure 4 shows how radar cloud-top heights are distributed, revealing that clouds were found at lower altitudes at CFARR compared to SGP. $\mathrm{CO}_{2}$ slicing overestimates cloud-top heights for mid-level clouds (Wielicki and Coakley, 1981; Baum and Wielicki, 1994), 
Table 1. Summary of all differences in cloud-top heights $(\mathrm{CTH})$ for both sites and all instruments. N represents the number of cases, $<\mathrm{A}>$ and $<\mathrm{B}>$ the average CTHs for each instrument and $<\mathrm{A}-\mathrm{B}>$ the average difference in CTH between instruments $\mathrm{A}$ and $\mathrm{B}$.

\begin{tabular}{|c|c|c|c|c|c|c|c|c|c|}
\hline \multirow{2}{*}{$\begin{array}{l}\text { Instruments } \\
\text { A }\end{array}$} & \multirow[b]{2}{*}{ B } & \multicolumn{4}{|c|}{ Statistics for SGP } & \multicolumn{4}{|c|}{ Statistics for CFARR } \\
\hline & & $\mathrm{N}$ & $\begin{array}{l}<\mathrm{A}> \\
(\mathrm{km})\end{array}$ & $\begin{array}{l}<\mathrm{B}> \\
(\mathrm{km})\end{array}$ & $\begin{array}{l}<\mathrm{A}-\mathrm{B}> \\
(\mathrm{km})\end{array}$ & $\mathrm{N}$ & $\begin{array}{l}<\mathrm{A}> \\
(\mathrm{km})\end{array}$ & $\begin{array}{l}<\mathrm{B}> \\
(\mathrm{km})\end{array}$ & $\begin{array}{l}<\mathrm{A}-\mathrm{B}> \\
(\mathrm{km})\end{array}$ \\
\hline MODIS CO2 & Radar & 22 & $8.8 \pm 1.4$ & $10.0 \pm 1.9$ & $-1.2 \pm 1.0$ & 10 & $7.4 \pm 1.7$ & $6.8 \pm 2.0$ & $0.6 \pm 1.3$ \\
\hline MODIS BT11 & Radar & 21 & $1.3 \pm 1.1$ & $2.7 \pm 2.3$ & $-1.4 \pm 2.8$ & 17 & $1.8 \pm 0.9$ & $2.2 \pm 2.0$ & $-0.5 \pm 2.3$ \\
\hline $\begin{array}{l}\text { MISR } \\
\text { (single) }\end{array}$ & Radar & 16 & $4.9 \pm 4.2$ & $5.5 \pm 4.4$ & $-0.6 \pm 0.6$ & 14 & $1.8 \pm 1.6$ & $1.9 \pm 1.4$ & $-0.2 \pm 0.5$ \\
\hline $\begin{array}{l}\text { MODIS CO2 } \\
\text { (single and with radar) }\end{array}$ & MISR & 7 & $8.8 \pm 1.1$ & $9.3 \pm 1.5$ & $-0.4 \pm 0.7$ & 1 & 8.4 & 7.0 & 1.4 \\
\hline $\begin{array}{l}\text { MODIS BT11 } \\
\text { (single and with radar) }\end{array}$ & MISR & 9 & $1.2 \pm 1.2$ & $1.4 \pm 0.6$ & $-0.2 \pm 1.4$ & 13 & $1.8 \pm 0.9$ & $1.4 \pm 0.6$ & $0.5 \pm 1.0$ \\
\hline $\begin{array}{l}\text { MODIS CO2 } \\
\text { (all cases with difference } \\
\text { less than } 3 \mathrm{~km} \text { ) }\end{array}$ & MISR & 14 & $9.1 \pm 1.7$ & $8.9 \pm 1.7$ & $0.2 \pm 1.2$ & 16 & $8.5 \pm 0.7$ & $8.4 \pm 1.5$ & $0.2 \pm 1.1$ \\
\hline $\begin{array}{l}\text { MODIS BT11 } \\
\text { (all cases) }\end{array}$ & MISR & 24 & $0.8 \pm 0.9$ & $1.6 \pm 0.8$ & $-0.8 \pm 1.2$ & 55 & $1.2 \pm 0.8$ & $1.4 \pm 0.5$ & $-0.3 \pm 0.8$ \\
\hline
\end{tabular}

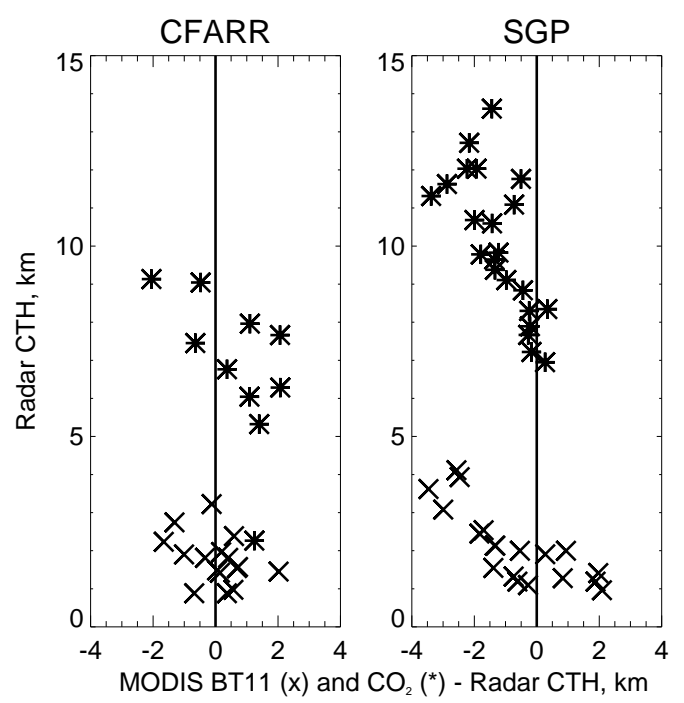

Fig. 4. Radar vs. difference MODIS - Radar cloud-top heights for CFARR (left) and SGP (right) distinguishing between BT11 cases (x) and $\mathrm{CO}_{2}$-slicing cases (*).

thus explaining some of the large positive differences for the clouds at CFARR. At SGP, clouds are mainly found above $7 \mathrm{~km}$; and in accordance with previous studies (Frey et al. 1999; Mace et al., 2005), MODIS $\mathrm{CO}_{2}$-slicing cloud-top heights appear underestimated for high thin clouds.

The 21 (out of 43) cases retrieved with BT11 at SGP showed a very poor correlation between MODIS and the radar cloud-top heights with a large average difference between MODIS and radar cloud-top heights of $-1.4 \pm 2.8 \mathrm{~km}$. Cases retrieved with BT11 at CFARR occurred on 17 (out of
27) occasions and the difference between MODIS and radar cloud-top heights was $-0.5 \pm 2.3 \mathrm{~km}$. The standard deviation and bias for BT11 heights at CFARR is less than that at SGP. MODIS retrievals of optical thickness exhibited a slight positive correlation with a difference between MODIS and radar cloud-top heights when BT11 is used. This correlation indicates that when clouds are optically thick, the MODIS BT11 cloud-top heights are above radar cloud-top heights, whereas when clouds are optically thin, the opposite is true. This is consistent with the assumption made with the BT11 technique that the cloud is opaque. Hence, the biases calculated at both sites are not systematic, but dependent on the distribution of optical thicknesses in the data-set.

\subsection{Intercomparison between MISR and radar-cloud-top heights}

There were fewer cases at both sites for comparison between MISR and radar because the BestWind stereo cloudtop heights are not always available. From the 43 cases available at SGP, 3 were found to lack a MISR stereo height retrieval (e.g. algorithm failure, cloud not detected) and 16 had a stereo height retrieval but without wind correction. At CFARR, from the 27 cases available for comparison, one lacked a stereo height retrieval and 5 had no wind retrievals. In this study, the cases with technical problems were excluded and we found that 40\% (SGP) and 19\% (CFARR) of all cloudy cases did not have a wind retrieval. The larger number of cases at SGP appears to result from stronger winds at this site that were highly variable across the scene, thus making the stereo wind retrieval more difficult.

Of the remaining cloudy cases, we found 24 cases (SGP) and 21 cases (CFARR) for which we could compare MISR 
and radar cloud-top heights. After discarding multilayer cloud cases, there were 16 (out of 43 originally) cases (SGP) and 14 (out of 27 originally) cases (CFARR) of singlelayered cloud cases (from inspection of the radar profiles). The resulting average differences between MISR and radar cloud-top heights were calculated as $-0.6 \pm 0.6 \mathrm{~km}$ (SGP) and $-0.2 \pm 0.5 \mathrm{~km}$ (CFARR). These results imply that MISR cloud-top heights show a slight low bias, mainly because the stereo technique is tuned to detect the area in the cloud that has the brightest contrast, which does not necessarily coincide with the highest levels in the cloud (Wylie et al., 1998). However, the low bias is slightly larger at SGP where clouds are at higher altitude (Fig. 5) and potentially have a lower optical thickness. The standard deviations are comparable and of the order of the theoretical estimate of $0.562 \mathrm{~km}$ (Moroney et al., 2002). Figure 5 indicates that some low-level clouds at CFARR display a positive difference, i.e. MISR cloud-top heights are sometimes higher than radar cloud-top heights, whereas all low-level MISR cloud-top heights at SGP show a low bias. This might be an indication of the CFARR radar loss in sensitivity.

\subsection{Intercomparison between MODIS and MISR cloud-top heights}

There were 16 single level cloud cases with both MISR and MODIS CTH retrievals over the radar site at SGP and 14 at CFARR. For 7 cases at SGP, the average difference between MODIS $\mathrm{CO}_{2}$-slicing and MISR cloud-top heights was $-0.4 \pm 0.7 \mathrm{~km}$. Unfortunately, only one case like this was found at CFARR; it had a difference of $1.4 \mathrm{~km}$. These differences confirm that MISR cloud-top heights are slightly higher than MODIS $\mathrm{CO}_{2}$-slicing cloud-top heights in single layer cloud situations. MODIS BT11 cloud-top height differences are $-0.2 \pm 1.4 \mathrm{~km}$ (SGP, 9 cases) and $0.5 \pm 1.0 \mathrm{~km}$ (CFARR, 13 cases); these differences are not consistent between the sites but the results from the previous sections suggest that the change in bias is dictated by the average optical depth of the clouds at each site. Clouds tend to be of greater optical depth at CFARR than SGP, so BT11 cloud-top heights will be more often overestimated at CFARR than SGP.

Multilayer cases are more likely to be processed with MODIS $\mathrm{CO}_{2}$-slicing rather than BT11 because the method is more sensitive to the presence of high level clouds. Consequently, we decided to compare MISR and MODIS for all available cases when BT11 is used. Here we found an average difference between MODIS BT11 and MISR cloud-top heights of $-0.8 \pm 1.2 \mathrm{~km}$ at SGP and $-0.2 \pm 0.8 \mathrm{~km}$ at CFARR (MISR-derived clouds were placed higher than MODIS clouds). The correlations are poor and the standard deviations indicate that the retrieved cloud-top heights from the two instruments are about $1 \mathrm{~km}$ from each other, on average. Figures 6 and 7 show, for the two sites, how the difference between MODIS and MISR cloud-top heights varies as a function of MODIS and MISR cloud-top heights. These figures confirm that for most low-level cloud cases, the MISR cloud-top heights appear slightly higher than MODIS cloud-



Fig. 5. Radar vs. Difference MISR - Radar cloud-top heights for single level cloud cases selected at CFARR (left) and SGP (right).

top heights when BT11 is used. These figures also show the cases where a radar profile was available and indicate when more than one cloud layer was present. For the SGP site, MISR cloud-top heights are higher than MODIS cloud-top heights when BT11 is used and also for some high clouds using the $\mathrm{CO}_{2}$-slicing retrieval method. The MODIS $\mathrm{CO}_{2}-$ slicing cloud-top heights compare well with MISR cloud-top heights with the exception of cases where the radar indicated multilayer situations.

For some multilayered cloud situations, the two instruments are in good agreement, meaning that for these cases the uppermost layer was of sufficient optical thickness for the MISR retrieval algorithm to detect it. These situations also show that multilayer situations with the uppermost layer of low optical thickness will exhibit differences in cloudtop heights (the differences are greater than $3 \mathrm{~km}$ ) between the two instruments. Consequently, if we only consider the cases for which the difference is smaller than $3 \mathrm{~km}$, we can be fairly certain that we have eliminated the multilayer cloud cases from the intercomparison pool. With this expanded data-set, we recalculated the difference between MODIS and MISR cloud-top heights; for 14 cases at SGP, the difference between MODIS $\mathrm{CO}_{2}$-slicing and MISR cloud-top heights was calculated as $0.2 \pm 1.2 \mathrm{~km}$, with a correlation coefficient of 0.7 and at CFARR for 16 cases the difference was $0.2 \pm 1.1 \mathrm{~km}$ with a correlation coefficient of 0.8 . The two sites gave virtually identical differences, which is quite exceptional considering the small number of cases and the different distributions in cloud-top heights. The standard deviations are close to $1 \mathrm{~km}$; the bias indicates that MODIS cloud-top heights are slightly higher than MISR cloud-top heights for mid- to high-level clouds, in contrast to the situation for low-level clouds discussed heretofore. 


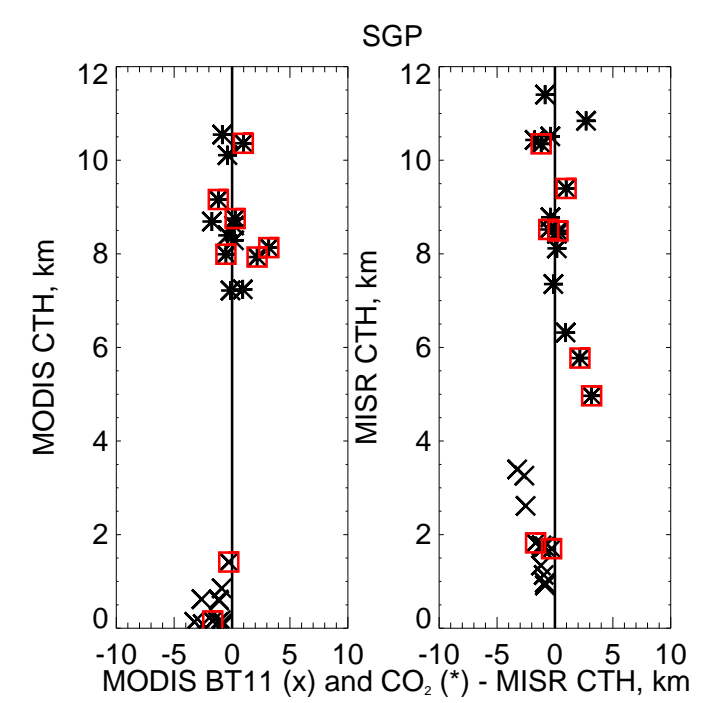

Fig. 6. MODIS (left) and MISR (right) cloud-top heights vs. the difference between MODIS and MISR cloud-top heights for all cases found at SGP, with BT11 cases marked as (x), $\mathrm{CO}_{2}$-slicing as (*) and cases with a radar retrieval and a multilayer situations squared.

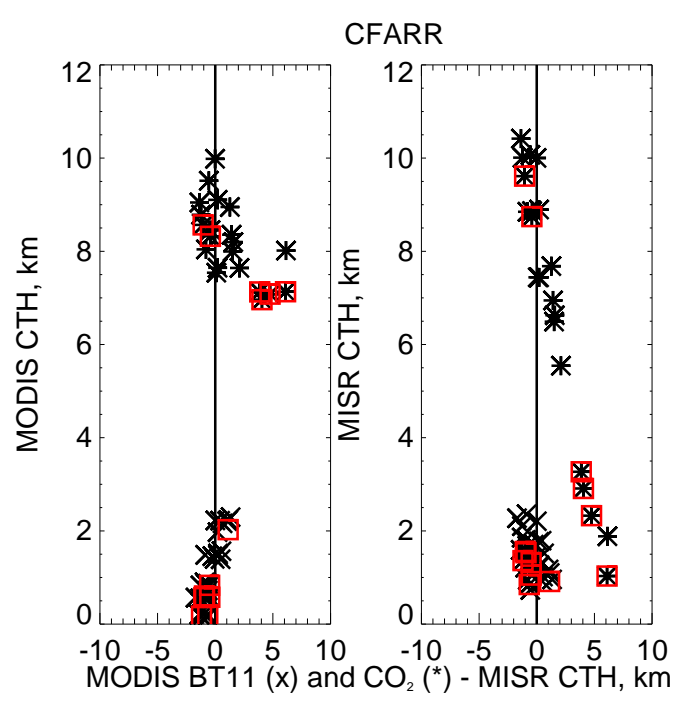

Fig. 7. MODIS (left) and MISR (right) cloud-top heights vs. the difference between MODIS and MISR cloud-top heights for all cases found at CFARR, with BT11 cases marked as (x), $\mathrm{CO}_{2}$-slicing as (*) and cases with a radar retrieval and a multilayer situations squared.

\section{Conclusions}

Ground-based radar measurements of cloud-top heights at the Atmospheric Radiation Measurement Southern Great Plains (SGP) and Chilbolton Facility for Atmospheric and Radio Research (CFARR) were used to assess the accuracy of the NASA Terra platform MODIS and MISR cloud-top height retrievals over the duration of the mission from March 2000 to October 2003.
We distinguish between MODIS retrievals performed with the $\mathrm{CO}_{2}$-slicing method from those performed with the 11$\mu \mathrm{m}$ brightness temperature method. Mid-level and highlevel cloud-top heights are usually retrieved with the former, with resulting differences between MODIS and radar cloud-top heights of $-1.2 \pm 1.0 \mathrm{~km}$ (SGP) and $0.6 \pm 1.3 \mathrm{~km}$ (CFARR). Radar measurements indicate that clouds at CFARR tend to reside at lower altitudes than for clouds at SGP. We conclude that either the CFARR radar could not fully detect high clouds or that MODIS cloud-top heights are overestimated for mid-level clouds. When only BT11 was used in the MODIS cloud-top height retrieval (meaning that a valid $\mathrm{CO}_{2}$ slicing result could not be obtained), a poor correlation was found between the radar and MODIS cloud-top heights. MODIS cloud-top heights tended to be underestimated for low optical thicknesses and overestimated for high optical thicknesses, with the difference between MODIS and radar cloud-top heights being $-1.4 \pm 2.8 \mathrm{~km}$ at SGP and $-0.5 \pm 2.3 \mathrm{~km}$ at CFARR.

The average difference between MISR wind corrected and radar cloud-top heights was $-0.6 \pm 0.6 \mathrm{~km}$ (SGP, 16 cases) and $-0.2 \pm 0.5 \mathrm{~km}$ (CFARR, 14 cases). The biases indicate a tendency for MISR cloud-top heights to be underestimated, due to the sensitivity of the cloud layer of highest contrast, with a larger bias at SGP than CFARR. This is partly due to a) the larger number of high clouds at SGP, b) high clouds being of lower optical thickness, in general, and c) possibly also indicating the loss of sensitivity of the CFARR radar. The standard deviations are confined to within $0.6 \mathrm{~km}$, in good agreement with the MISR theoretical accuracy of $0.562 \mathrm{~km}$ (Moroney et al., 2002).

MODIS and MISR cloud-top heights were also intercompared, and the results appear consistent with their individual comparisons with radar. For both MODIS retrieval techniques, the standard deviations are approximately $1 \mathrm{~km}$, suggesting that, although both instruments provide similar estimates of cloud-top heights, MISR cloud-top heights tend to be of greater accuracy when compared to the radar measurements. For the cases with MISR and MODIS BT11 cloudtop heights, regardless of the number of cloud layers, the bias that was found between MODIS and MISR cloud-top heights was $-0.8 \mathrm{~km}$ and $-0.3 \mathrm{~km}$ at SGP and CFARR, respectively. One can surmise a) for both sites, the biases are consistent with the individual comparisons with the radar cloud-top heights; b) the biases are negative, suggesting MISR cloudtop heights are slightly higher than MODIS BT11 cloud-top heights; c) the bias is smaller at CFARR than SGP, suggesting that low clouds at CFARR have higher optical thicknesses than at SGP. Comparing MODIS $\mathrm{CO}_{2}$-slicing with MISR cloud-top heights, the corresponding bias was $0.2 \mathrm{~km}$ at both sites, indicating that MODIS $\mathrm{CO}_{2}$-slicing cloud-top heights were slightly higher than MISR cloud-top heights, in particular for mid-level clouds. The differences did not correlate with MODIS optical thicknesses, presumably because the latter correspond to the total atmospheric column rather than to the highest (first observable) cloud layer. 
Although this assessment was performed at only two sites situated in the northern mid-latitude region, they offer a variety of cloud characteristics. The distribution of cloudtop heights and optical thicknesses at each height may be different from one site to the next. The main cause of inaccuracy in the cloud-top height estimates was found to be individual cloud layer optical thickness, where regions with thin high clouds lead to the differences in MODIS and MISR retrievals. We also verified (but not shown here) that there were no major differences in results obtained in winter and summer months. These results are encouraging for the development of a new cloud climatology, as this study reveals a complementarity between both instruments that would allow more precise measurements for low clouds with MISR retrievals and for higher clouds in a multilayer situation with MODIS retrievals.

More precise information on cloud optical thickness would improve our assessment. This can only be achieved on a global scale by using a lidar (for cloud optical depths $\leq 3$ ) and radar (for optically thick clouds) in space, coincident with Terra observations. The Geoscience Laser A1timeter System (GLAS) instrument (Zwally et al., 2002) onboard the Ice, Cloud and Land Elevation satellite (ICESat) platform, launched on 12 January 2003, is a suitable candidate instrument, as well as the soon-to-be-launched CloudAerosol Lidar and Infrared Pathfinder Satellite Observation (CALIPSO) and the CLOUDSat radars. The last two instruments are part of the so-called A-train constellation that includes the AQUA platform with MODIS on-board and allows small time differences between MODIS and the active instruments observations. Comparisons with MISR on-board TERRA will be problematic due to the 3-h time delay, the likelihood of substantial variation in CTH and cloud properties during that period. Given this, additional information on cloud-top winds will be necessary.

Both MODIS and MISR data are to be reprocessed again for the entire duration of the TERRA mission, producing a collection 5 for MODIS and a collection 4 for MISR, with the former available in early 2006 and the latter in mid 2006. Significant improvement is expected in the MODIS cloudtop pressure, due to algorithm enhancements, as well as mitigation of issues related to detector striping and mirror emissivity characterization.

Acknowledgements. This research was supported at University College London by the European Commission under contract EVG1CT-2000-00033 (CLOUDMAP2), at the Pennsylvania State University by JPL contract 1259588 , and at the University of Wisconsin in Madison by NASA contract NAS5-31367. The ECMWF data are courtesy of the BADC (http://www.badc.rl.ac.uk). The MISR data products collection 3 (version F05) were obtained from the NASA Langley Research Center Atmospheric Sciences DAAC and the MODIS Collection 4 data from the Goddard Earth Sciences DAAC. The authors would like to thank Elizabeth Slack (RAL) for providing some of the CFARR radar data. The radar data for the ARM SGP site were obtained from the Atmospheric Radiation Measurement program archive located at the Department of Energy Oak Ridge National Laboratory.
Topical Editor F. D'Andréa thanks two referees for their help in evaluating this paper.

\section{References}

Ackerman, S. A., Strabala, K. I., Menzel, W. P., Frey, R. E., Moeller, C. C., and Gumley, L. E.: Discriminating clear sky from clouds with MODIS, J. Geophys. Res., 103, 32 141-32 157, 1998.

Baum, B. A. and Wielicki, B. A.: Cirrus cloud retrieval using infrared sounding data: multilevel cloud errors, J. Appl. Meteorol. 33, 107-117, 1994.

Clothiaux, E. E., Ackermann, T. P., Mace, G. C., Moran, K. P., Marchand, R. T., Miller, M. A., and Martner, B. E.: Objective determination of cloud-top heights and radar reflectivities using a combination of active remote sensors at the ARM CART sites, J. Appl. Meteorol., 39, 645-665, 2000.

Derber, J. C., Parrish, D. F., and Lord, S. J.: The new global operational analysis system at the National Meteorological Center, Weather Forecasting. 6, 538-547, 1991.

Diner, D. J., Beckert, J. C., Reilly, T. H., Bruegge, C. J., Conel, J. E., Kahn, R. A., Martonchik, J. V., Ackermann, T. P., Davies, R., Gerstl, S. A. W., Gordon, H. R., Muller, J.-P., Mynemi, R. B., Sellers, P. J., Pinty, B., and Verstraete, M.: Multiangle Imaging SpectroRadiometer (MISR) Instrument description and experiment overview, IEEE trans., Geosci. Rem. Sens., 36, 1072-1087, 1998.

Frey, R., Baum, B. A., Menzel, W. P., Ackerman, S. A., Moeller, C. C., and Spinhirne, J. D. : A comparison of cloud-top heights computed from airborne lidar and MAS radiance data using $\mathrm{CO}_{2}$-slicing, J. Geophys. Res., 104, D20, 24 547-24 555, 1999.

Hasler, A. F.: Stereographic observations from satellites: An important new tool for the atmospheric sciences, Bull. Amer. Meteor. Soc., 62, 194-212, 1981.

King, M. D., Menzel, W. P., Kaufman, Y. J., Tanré D., Gao, B. C., Platnick, S., Ackerman, S. A., Remer, L. A., Pincus, R., and Hubanks, P. A.: Cloud, Aerosol and Water Vapor Properties from MODIS, IEEE Trans. Geosci. Remote Sens., 41, 442-458, 2003.

Mace, G. G., Zhang, Y., Platnick, S., King, M. D., Minnis, P., and Yang, P.: Evaluation of cirrus cloud properties derived from MODIS data using cloud properties derived from ground-based observations collected at the ARM SGP site, J. Appl. Meteorol., 44, 221-240, 2005.

Marchand, R. T., Ackerman, T. P., King, M. D., Moroney, C., Davies, R., Muller, J.-P. A. L., and Gerber H.: Multiangle observations of Arctic clouds from FIRE ACE: June 3, 1998, case study, J. Geophys. Res., 106, D14, 15 201-15 214, 2001.

Menzel, W. P., Smith, W. L., and Stewart, T. R.: Improved cloud motion wind vector and height assignment using VAS, J. Clim. Appl. Meteorol. 22, 377-384, 1983.

Menzel, P., Baum, B., Strabala, K., and Frey, R.: Cloud-top properties and cloud phase algorithm theoretical basis document, ATBD_MOD_04, NASA Goddard Space flight center, 2002.

Moroney, C., Davies, R., and Muller, J.-P.: Operational Retrieval of Cloud-top Heights Using MISR Data, IEEE Trans. Geosci. Remote Sens., 40, 1532-1540, 2002.

Muller, J.-P., Mandanayake, A., Moroney, C., Davies, R., Diner, D. J., and Paradise, S.: MISR stereoscopic image matchers: Techniques and results, IEEE Trans. Geosci. Remote Sensing., 40, 1547-1559, 2002.

Naud, C., Muller, J.-P., and Clothiaux, E. E.: Comparison of cloud top heights derived from MISR stereo and MODIS $\mathrm{CO}_{2}$-slicing, 
Geophys. Res. Lett., 29, 16, 1795, doi:10.1029/2002GL015460, 2002.

Naud, C., Muller, J. P., Haeffelin, M., Morille, Y., and Delaval, A.: Assessment of MISR and MODIS cloud top heights through inter-comparison with a back-scattering lidar at SIRTA, Geophys. Res. Lett., 31(4), L04114, 2004.

Platnick, S, King, M. D., Ackerman, S. A., Menzel, W. P., Baum, B. A., Riédi, J. C., and Frey, R. A.: The MODIS cloud products: algorithms and examples from Terra, IEEE Trans. Geosci. Remote Sens., 41, 459-473, 2003.

Salomonson, V. V., Barnes, W. L., Maymon, P. W., Montgomery, H. E., and Ostrow, H.: MODIS: Advanced facility instrument for studies of the earth as a system, IEEE Trans. Geosc. Remote Sens., 27, 145-153, 1989.

Schiffer, R. A. and Rossow, W. B.: The international satellite cloud climatology project (ISCCP): the first project of the world climate research programme, Bull. Am. Meteorol. Soc., 64, 779-784, 1983.

Wielicki, B. A. and Coakley, J. A.: Cloud retrieval using infrared sounder data: Error analysis, J. Appl. Meteorol., 20, 157-169, 1981.
Wylie, D. P. and Menzel, W. P.: Two years of cloud cover statistics using VAS, J. Clim., 2, 380-392, 1989.

Wylie, D. P., Santek, D., and Starr, D. O'C.: Cloud-top heights from GOES-8 and GOES-9 stereoscopic imagery, J. Appl. Meteorol., 37, 405-413, 1998.

Wylie, D. P. and Menzel, W. P.: Eight years of global high cloud statistics using HIRS, J. Climate, 12, 170-184, 1999.

Zong, J., Davies, R., Muller, J. P., and Diner, D. J.: Photogrammetric retrieval of cloud advection and top height from the Multiangle Imaging Spectroradiometer (MISR), Photogrammetric Engineering and Remote Sensing, 68, 821-830, 2002.

Zwally, H. J., Schutz, B., Abdalati, W., Abshire, J., Bentley, C., Brenner, A., Bufton, J., Dezio, J., Hancock, D., Harding, D., Heering, T., Minster, B., Quinn, K., Palm, S., Spinhirne, J., and Thomas R.: ICESat's laser measurements of polar ice, atmosphere, ocean, and land, Journal of Geodynamics, 34, 405-445, 2002. 